\title{
Mobile Applications to Improve Emotional Intelligence in Autism - A Review
}

\author{
https://doi.org/10.3991/ijim.v12i6.9073 \\ Chara Papoutsi, Athanasios Drigas $(\bowtie)$ \\ National Centre for Scientific Research "Demokritos", Athens, Greece \\ dreit.demokritos.gr \\ Charalabos Skianis \\ University of the Aegean, Samos, Greece
}

\begin{abstract}
The ability to understand and regulate emotions in ourselves and others is essential for the healthy development of all human beings. It helps people comprehend themselves and other people, it guides response and decision making and enhances the capacity to develop social relationships. People with Autistic Spectrum Disorders have deficiencies in Emotional Intelligence skills and that leads to difficulties in understanding themselves and the people in their social environments in relation to emotions, feelings and thoughts. The usability of mobile applications developed for children and adolescents with ASD is important because it gives the opportunity to practice in an accessible and creative way to enhance their emotional intelligence. The current article aims to carry out a systematic review of mobile applications on improving emotional intelligence in children and adolescents with Autistic Spectrum Disorders.
\end{abstract}

Keywords-Mobile Technology, Applications, Autistic Spectrum Disorders, Emotions, Emotional Intelligence

\section{$1 \quad$ Introduction}

\section{$1.1 \quad$ Autistic Spectrum Disorder}

Autistic Spectrum Disorder (ASD) is a neurodevelopmental disorder that begin early in life [1]. The beginning of ASD has been studied extensively and it has been noticed that the time when somebody is diagnosed with autistic spectrum disorders may be much later than the time of onset of the disorder [2,3]. Kanner first talked about autism in 1943 [4]. According to Kanner's perspective, autism represented a peculiar pattern of behavior from birth or before 30 months. He mentioned this as "early infantile autism [5]." The autistic disorders are recognized as medical categories in both international systems for the classification of diseases [6,7], based on a set of characteristics that represent generic descriptive domains and not specific behaviors.

Autistic spectrum disorders are characterized by difficulties in social communication and interaction in various social contexts, as well as limited and recurring patterns of 
behavior, interests and activities [8]. A series of symptoms in multiple areas, including cognitive, behavioral, emotional and sensory symptoms are also presented. Sleeping and eating difficulties, synesthesia, as well as emotional dysfunction, and difficulties with initiation, planning, and organization are often occurred [9].

\subsection{Autistic Spectrum Disorder and Emotional Intelligence}

People with Autistic Spectrum Disorder (ASD) is observed to have deficits in emotional intelligence skills. These deficits are related to difficulties in understanding, expressing and regulating their emotions, in understanding the emotions and the feelings of other people and in showing signs of empathy. In addition to, and consequently, there are difficulties in social interaction and communication and a weak integration of social-emotional behaviors [10-12]. Studies have shown deficits in emotional intelligence and in facial emotion recognition, which is an important aspect of EI, in both children $[13,20,21]$ and adults $[14,15,20]$ with autism. People suffering from ASDs also have impairments in encoding emotional and social information from facial stimuli [16]. Even though most of the studies have focused on face stimuli, there are surveys that indicate that the abnormalities of emotion processing may also be present in other types of visual stimuli such as body movement $[17,18]$. Persons with ASD may also have atypical cellular shapes in the nervous system [19], some of which can be monitored by surface skin sensors such as a pair of electrodes and a small circuit that measures the conduction of the skin.

Emotion is often defined as a complex feeling which results in physical and psychological changes affecting thought and behavior [22]. It includes feeling, thought, nervous system activation, physiological changes, and behavioral changes such as facial expressions [23]. Emotions seem to dominate many aspects of our lives as we must recognize and respond to important events related to survival and/or the maintenance of prosperity and, therefore, emotions serve various functions [24].

On the other hand, Emotional Intelligence is the ability to identify, understand, and use emotions positively to manage anxiety, communicate well, empathize, overcome issues, solve problems, and manage conflicts $[25,26]$. According to the Ability EI model, it is the perception, evaluation, and management of emotions in yourself and others [27]. Emotional Intelligence (EI), or the ability to perceive, use, understand, and regulate emotions, is a relatively new concept that attempts to connect both emotion and cognition [28]. With emotional intelligence you acknowledge, accept, and control your own emotions and emotional reactions as well as those of other people.

\subsection{Autistic Spectrum Disorders, Mobile Applications and Emotional Intelligence}

eImpairments in emotional intelligence seem to be quite permanent in children and adolescents with ASD. For that purpose, mobile applications have been designed to help these people improve their emotional intelligence skills such us emotion recognition and emotion regulation. 
Mobile devices are shaping the lifestyle of users by bringing about changes in the field of socialization, implementation of actions and adoption of new habits [29]. Fogg and Eckles (2007) [30] had pointed out that mobile phones will become the most important platform for changing human life and behavior radically. Oinas-Kukkonen (2008) [31] argues that technology is evolving, and information systems are trying to create new ways of disseminating information by creating new opportunities and opening new horizons for a better way of life.

The spread of mobile phones into our lives is an evidence of their popularity [32]. The constantly growing preference and adoption of mobile phones reflects their potential to promote health and general wellbeing of users. Portability, rapid and continuous dissemination of data, advanced computing power and easy dissemination of applications give them an advantage in relation to other forms of information and communication technologies [32].

Mobile applications have made major changes in many areas of human life such us health [32-37]. They provide the opportunity and have promised to help people change social behavior [38-40], enrich education [41-43] and promote well-being [44-46]. There is also an effort, and apps have already been developed to identify or develop emotions in people and children [47]. Particularly, great steps have been taken to create mobile applications for people with autistic spectrum disorders.

Mobile devices serve as an augmentative and alternative communication (AAC) in the pocket and had since gained popularity because of its flexible multimedia content and storage, portability, mobility and affordability [48]. Mobile technologies can help autistic people and their social environment in the field of education, communication and in issues that have to do with their personal basic needs. In addition, the connection between mobile devices is very useful for communicating and learning activities in a team environment, helping the user to integrate into his/her social environment.

Most autistic pupils tend to have more visual capabilities and mobile technology is attractive to them [49]. They enjoy using smart phones and tablets to learn and play because of their simplicity and the engaging environments with lively colors and a lot of apps have been developed with these characteristics. More specifically applications have been designed for the detection and cultivation of emotions and emotional intelligence in children and adolescents with autism [50].

Our research has concentrated on collecting mobile applications designed to enhance emotional intelligence skills to children and adolescents with ASD. We provide a systematic review of current mobile apps that are intended to improve emotional understanding and emotional regulation.

\section{Literature Review}

Madsen et al. (2008) used Samsung's ultramobile computers and create the application 'Just-In-Time In-Situ' to help pupils with autistic spectrum disorders to capture and analyze their social and emotional interactions with their peers. The ultramobile computers give the opportunity to interact with people in a live setting and through visible facial communication pupils can see and learn their own and others' social- 
emotional states. They can gradually perceive in real time how somebody is feeling from the things he says or the movements he makes and moreover they can see the reflection that their responses have on others through facial expressions and that will help in the conversations in their daily life. Emotion Bubbles interface have been designed to provide information about levels of emotions in a simple way that would be easily understandable for individuals with spectrum disorders [51].

'HANDS' is a project belonging to the mobile technology which aims to improve the life of teenagers who have been diagnosed with autistic spectrum disorders. HANDS is a toolbox which is implemented on their personal smart-phones. It has been designed by teenager's teachers in cooperation with the teenagers and other researchers. Its aim is to reinforce the teenagers by helping them obtain independence in their daily life and social and self-management skills. The toolbox includes improvements of emotional skills too which is part of social ones. All these help teenagers have better and constructive social integration and inclusion $[52,53]$.

'Wrong Planet' (Jordan, 2010) is a web community designed for individuals with Autism, Asperger's Syndrome and other neurological differences. The web community is also addressed to the parents of these people and the professionals who are occupied with special needs. In the forum, autistic pupils socialize on their own by taking part in online conversations and can read articles that inform them about daily issues and how to deal with them. The most significant feature is that the autistic individual feels free to communicate with the world, without any social anxiety and with much engrossed empathy [54].

'Proyect@ Emociones' is a multi-touch application which firstly designed for the ASD affected children of Chile. The software was developed using the User Centered Design (UCD) Methodology. The application helps pupils with autism learn about emotions, recognize emotions and improve social abilities as well as confidence and interactions with their own environment. The most important aim of this application is to develop the skill of empathy in the target children. It has several levels of complexity, funny images and feedback so the kids can enjoy the game and have the willing and the motive to continue participating. This app is free and available through Google Play. Currently, more than 7,000 downloads have been exceeded in Spanish-speaking countries [55-57].

Alves et al. (2013) presented the 'LIFEisGAME' prototype-Ipad version, a game that promotes facial emotion recognition and helps people with ASD to understand emotions so to develop empathy using real-time automatic facial expression analysis and virtual character synthesis. The game includes evolutionary stages that are progressively contributing to the recognition and expression of emotions. The avatars are faces of characters, faces of the people who play the game and faces of people the participant is familiar with in order to help feel more comfortable and facilitate the learning process. The LIFEisGAME prototype was tested on 11 children with ASD, ages ranging from 5 to 15 years old and was played during a 15 -minute game period. The results showed the usefulness of the game to promote emotional comprehension, offering positive results in the quality of life of children with autism [58,59].

'CaptureMyEmotion' (Gay et al., 2013) is an Android App that uses wireless biosensors to capture physiological data together with facial expression recognition to 
provide a very personalized way to help autistic children discuss and learn about their emotions. The application gives the opportunity to the child to take photos, videos or sounds, attach emotion data and a self-portrait photo and to comment on them and the emotions that are showed with a caregiver at a later stage. CaptureMyEmotion has the potential to help autistic children understand their emotions and their emotional reactions and consequently their better integration in the society. Other applications that follow the same mindset for recognizing the user's emotional state from facial expressions using smartphones are 'FaceFetch' (Mahesh et Al, 2012) and 'Beyond Touch' (Anand, 2012) [60-62].

Tan et al. (2013) presented a touch-based tablet game application designed for an iPad, 'Can you CopyMe', for the recognition, expression and understanding of emotions in a funny and engaging way. Photographs with real human faces are depicted in the screen and the child has to mimic their emotional expressions which are written underneath it whilst watching his/her own face in a live video. The game detects if the emotional expression is valid and if so the game is continued. Otherwise, it provides feedback and reinforcement to the child to mimic the expression again. It has three levels of difficulty. However, its founders want to perform a larger scale user study for higher validity. Similar applications for the promotion of social-emotional development are 'Video Modeling Imitation Training' (Cardon, 2012), 'Emotion Mirror' (Deriso et al. 2012), 'iPad play story' (Murdock et al. 2013), and 'EmoTrain' (Tsangouri et al. 2016) [63-67].

'Autisay' (Voon et al. 2015) is a mobile application for the communication between the autistic child, who has difficulties in communication verbally, and his/her caregivers. It has been designed for the improvement of social communication of the children with ASD and simultaneously that feature contributes to a better quality of life for the child and the people around him/her. The Autisay has three big categories for the child to learn and express his/her needs: (1) Life Skills, (2) Communication and (3) Activities. As for the Communication feature the child can learn and express his/her feelings by touching on one of the icons and a voice verbally express that emotion. Moreover, the child can learn to express new emotions and needs because the caregiver can embody new emotions pictorially on the template and record them vocally. Another application that it is in the same spirit is 'EducateMe' by Institut Teknologi Brunei [68,69].

'Zirkus Empathico', a mobile application, is a playful empathic training that helps children strengthen their socio-emotional abilities. The application is specifically designed to train children to deal with their autism or other behavioral difficulties in a playful way. In this way, children learn faster and easier. It is an educational application to teach children how to express feelings and how to interpret other people's expressions. It focuses on enhancing socio-emotional skills in the daily interaction and communication of pre-primary and primary school children. In five games, children learn how to express, interpret and react to the feelings of others to simplify social interactions. In addition, the application can also be used by healthy children for reinforcement and preventative purposes [70,71].

The 'GameBook' presents the story of Tobias' adventure during a visit to a zoo park. The player can read the story by text or listen to it by sound. The game's environment strengthens the interest of the users and the virtual character is designed in such a way 
that it is attractive and accessible for the user to work with him empathically. The game has five scenarios that involve the child in real life situations related to emotions. It interacts with the environment of the zoo where events are occurred, social and emotional situations are created, and the child must recognize the 3D avatar's feelings choosing the right one for each situation to move on to the next level. It can be played on any mobile device [72,73].

Shen et al. (2016) presented 'My Drama', a story-based game application which was developed for young people with autism to help them with emotion recognition, understanding and expression of emotions in social context and gain empathy with others. The game contains elements of drama therapy and mobile game design but also has playful elements to be more attractive and interesting to pupils. In the story, Ben's sister, Sanneke, was caught by an evil witch who stole emotions form fairies and turned them into stones. It is Ben's mission to save Sanneke and the fairies by completing tasks with emotions. Everything is taking place into a consistent story and the users take the perspective of the cartoon character and collect, related to the story, emotional expression photographs in a known environment. The results of a pilot test show that my Drama is a promising educational tool for understanding emotions while the collection of photographic emotional expressions has increased communication. Similar applications about emotional development mostly demonstrative are 'Autism Emotion', 'Between the Lines' [74-76].

'What's the Expression - All Ages' is a mobile application in which children with autistic spectrum disorders can choose their favorite character through some options and learn how to express different emotions by watching the character's face and answer questions (WebTeam Corporation). With 'Touch and Learn - Emotions' children can learn to read emotions and body language by looking at colorful and vividly pictures with faces and choose the right facial emotional expression after hearing an emotion word. Parents, teachers and therapists can adapt their own voices and faces in the application (Innovative Mobile Apps Ltd (C) Alligator Apps). 'Emotions and Feelings Social Story' is an application about emotions and feelings which includes a social story that helps children understand how a person feels, why and when he or she is feeling that way, and which can be the causes of the feelings or the emotions that are expressed by the character. The user can choose either the story where he/she will learn about different emotions and their causes or can visit the 'Emotions and Feelings' page where there are buttons with different emotions and feelings from the story that say the word when pushed (Touch Autism). 'Autimo-Discover Emotions' helps children understand emotions with three funny games, many colorful pictures, videos and sounds. It focuses on learning the six basic emotions (happy, sad, surprised, angry, sick, afraid). Statistics to track progression are also available (Auticiel). 'Emotions 2 from I Can Do Apps' is an educational tool for emotional, speech and language development for individuals with Autism Spectrum Disorders and language disabilities. It is an application for identifying emotional facial expressions using real faces and social scenarios with levels of difficulty. It includes more complex emotions and continual feedback (I CAN DO APPS, LLC) [77-81].

'Learn with Rufus: Feelings and Emotions' aims to help children recognize simple and difficult feelings and emotions, to learn how each emotion is expressed and to 
name them. The game is highly customizable to meet the needs of children with different skills, ability levels, and learning styles. Fun reward sets, music, sounds, on-screen finger painting are some other options of the application (Rufus Robot, Inc.) 'Let's Learn Emotions PRO - Emotion Recognition for Speech Pathology \& Special Education' is an interactive application for the identification of emotions with flashcards and interesting and funny games. Flashcards allow users to exercise in guessing what facial expressions correspond with each emotion. There are also two matching games where the user must match facial expressions with the right emotions, a discussion game where users express themselves and talk about emotions and a memory game. It is designed to be flexible and ease to handle (Everyday Speech). 'Discovering Emotions with Zeely' is an educational application to teach emotions to children with ASD and other disorders. Obo, a game remote, and Zeely, an astronaut, are the main characters that come to earth to explore and help children learn about emotions in a fun and attractive way. It is easy to use with three learning modes having increasing difficulty. Collection of data and reporting tools are helpful for specialists, teachers, parents to note the progress of the child in the emotion recognition sector (Virtual Eye See Inc.). 'LOOK AT Me' is a training application for the improvement of making eye contact and recognizing emotional facial expressions in children with autistic spectrum disorders. The child through seven mini games-missions is trained to understand emotions by looking at faces in pictures and to express its own emotions. It is simple in use and meets the needs of the child. Awards, music and sounds are also available taking into consideration the preferences of the children (Samsung) [82-85].

Torrado et al. (2017) developed an assistance system for monitoring and interaction, based on the acquired physiological and motion signals of a smartwatch, in order to help people with autistic spectrum disorders and behavioral issues through customized emotional self-regulation strategies together with a tool for smartphones that is going to be used by caregivers or family members to create and edit these strategies, in an adaptive way. The smartwatch system detects the user's inner state and displays the emotional self-regulation strategies, when the user's heart rate exceeds the adjustable limit [86].

\section{Discussion}

People with ASD have inadequacies in expressing and recognizing emotions. The emotion recognition skills of individuals with ASD may to improve with age, even though they do not seem to achieve the level of typically developing individuals [87]. Consequently, they face up difficulties with themselves, with other peers and generally with their social relationships. Therefore, a variety of mobile applications have been designed to enhance emotional skills to children and adolescents with ASD from an early age of their life so as to help them in the future as well.

There are several advantages of using mobile devices as assistive tools. Firstly, they are easy and intuitive to use. The user can handle the mobile, use its programs and play games only with touching the screen and that makes it accessible to populations with intellectual disabilities and sensory motor difficulties. Secondly, mobile apps are well 
suited to the learning needs of the individuals with ASD because they are visually engaging and provide a consistent, predictable learning environment [88]. Finally, mobile devices are easy to transfer everywhere because it can fit into any individual's pocket and can be used anywhere and at any time. Thus, children and adolescents with ASD can directly transport these devices and use them in everyday situations, including those that promote social real-life interactions with other peers and people respectively [89].

Emotion-aware apps will significantly help these people to improve their emotional intelligence and might allow them to better integrate into social contexts. Mobile applications related to emotions can help people with ASD to understand the mind of others and may prevent them from experiencing negative series of vicious circles and possibly reduce their psychiatric comorbidity. Mobile applications will also help their caregivers, their educators and their parents to better understand them and make better informed decisions [90].

The philosophy of most applications with or without gamifications aspects as a first step is about helping children and adolescents understand, recognize and express the basic emotions. As a step second step there are apps which have progressively more complex emotions. Furthermore, other apps use photos with real faces sometimes known to the user which express emotions and the users by mimicking them learn about feelings and their expression. Moreover, from the research findings a few apps start supporting visible facial communication in a real setting encouraging peer social interaction and some other apps help people with ASD identify emotions in social situations in social stories.

Autistic people enjoy using technology, so using a mobile application might be attractive and beneficial to them. However, it is important to create more applications that respond to the peculiarities of autistic people, taking into consideration that interface design and varied categories will be important for them [91]. Apps that link facial emotions and everyday social situations should be developed. Emotion-aware apps that focus on body language and hands gesture are also essential to everyday social interactions. Challenges, real-time feedbacks and motives are also needed to help people with ASD develop and cultivate their emotional intelligence. Thus, it is important to examine and develop new intervention tools to teach emotion recognition strategies at an early stage to individuals with ASD. Mobile devices create new options and opportunities for programmers to create innovative instructional content that is appropriate for a diverse group of learners and diverse learning styles.

\section{$4 \quad$ References}

[1] Lauritsen, M. B. (2013). Autism spectrum disorders. European child \& adoles-cent psychiatry, 22(1), 37-42. https://doi.org/10.1007/s00787-012-0359-5

[2] Ozonoff, S., Heung, K., Byrd, R., Hansen, R., \& Hertz-Picciotto, I. (2008). The onset of autism: patterns of symptom emergence in the first years of life. Autism research, 1(6), 320328. https://doi.org/10.1002/aur.53

[3] Yirmiya, N., \& Charman, T. (2010). The prodrome of autism: early behavioral and biological signs, regression, peri-and post-natal development and genetics. Journal of Child Psychology and Psychiatry, 51(4), 432-458. https://doi.org/10.1111/j.1469-7610.2010.02214.x 
[4] Wing, L. (1996). Autistic spectrum disorders.

[5] Kanner, L. (1943). Autistic disturbances of affective contact. Nervous child, 2(3), 217-250.

[6] World Health Organization. (1992). The ICD-10 classification of mental and behavioural disorders: clinical descriptions and diagnostic guidelines (Vol. 1). World Health Organization.

[7] American Psychiatric Association (1994) Diagnostic and Statistical Manual of Mental Disorders, 4th edn. Washington, DC: American Psychiatric Association.

[8] Weston, L., Hodgekins, J., \& Langdon, P. E. (2016). Effectiveness of cognitive behavioural therapy with people who have autistic spectrum disorders: A sys-tematic review and metaanalysis. Clinical psychology review, 49, 41-54. https://doi.org/10.1016/j.cpr.2016.08.001

[9] Wiggins, L. D., Levy, S. E., Daniels, J., Schieve, L., Croen, L. A., DiGuisep-pi, C., ... \& Reynolds, A. (2015). Autism spectrum disorder symptoms among children enrolled in the Study to Explore Early Development (SEED). Journal of autism and developmental disorders, 45(10), 3183-3194. https://doi.org/10.1007/s10803-015-2476-8

[10] El Kaliouby, R., Teeters, A., \& Picard, R. W. (2006, April). An exploratory social-emotional prosthetic for autism spectrum disorders. In Wearable and Im-plantable Body Sensor Networks, 2006. BSN 2006. International Workshop on (pp. 2-pp). IEEE.

[11] Klin, A., Saulnier, C. A., Sparrow, S. S., Cicchetti, D. V., Volkmar, F. R., \& Lord, C. (2007). Social and communication abilities and disabilities in higher functioning individuals with autism spectrum disorders: The Vineland and the ADOS. Journal of autism and developmental disorders, 37(4), 748-759. https://doi.org/10.1007/s10803-006-0229-4

[12] Hudepohl, M. B., Robins, D. L., King, T. Z., \& Henrich, C. C. (2015). The role of emotion perception in adaptive functioning of people with autism spec-trum disorders. Autism, 19(1), 107-112. https://doi.org/10.1177/1362361313512725

[13] Celani, G., Battacchi, M. W., \& Arcidiacono, L. (1999). The understanding of the emotional meaning of facial expressions in people with autism. Journal of autism and developmental disorders, 29(1), 57-66. https://doi.org/10.1023/A:1025970600181

[14] Adolphs, R., Sears, L., \& Piven, J. (2001). Abnormal processing of social in-formation from faces in autism. Journal of cognitive neuroscience, 13(2), 232-240. https://doi.org/10.1162/ 089892901564289

[15] Pelphrey, K. A., Sasson, N. J., Reznick, J. S., Paul, G., Goldman, B. D., \& Piven, J. (2002). Visual scanning of faces in autism. Journal of autism and de-velopmental disorders, 32(4), 249-261. https://doi.org/10.1023/A:1016374617369

[16] Baron-Cohen, S., Wheelwright, S., Hill, J., Raste, Y., \& Plumb, I. (2001). The "Reading the Mind in the Eyes" Test revised version: a study with normal adults, and adults with Asperger syndrome or high-functioning autism. The Journal of Child Psychology and Psychiatry and Allied Disciplines, 42(2), 241-251. https://doi.org/10.1111/1469-7610.00715

[17] Hubert, B., Wicker, B., Moore, D. G., Monfardini, E., Duverger, H., Da Fonseca, D., \& Deruelle, C. (2007). Brief report: recognition of emotional and non-emotional biological motion in individuals with autistic spectrum disorders. Journal of autism and developmental disorders, 37(7), 1386-1392. https://doi.org/10.1007/s10803-006-0275-y

[18] Philip, R. C. M., Whalley, H. C., Stanfield, A. C., Sprengelmeyer, R., Santos, I. M., Young, A. W., ... \& Hall, J. (2010). Deficits in facial, body movement and vocal emotional processing in autism spectrum disorders. Psychological medicine, 40(11), 1919-1929. https://doi.org/10.1017/S0033291709992364

[19] Hirstein, W., Iversen, P., \& Ramachandran, V. S. (2001). Autonomic responses of autistic children to people and objects. Proceedings of the Royal Society of London B: Biological Sciences, 268(1479), 1883-1888. https://doi.org/10.1098/rspb.2001.1724 
[20] Mazefsky, C. A., Herrington, J., Siegel, M., Scarpa, A., Maddox, B. B., Sca-hill, L., \& White, S. W. (2013). The role of emotion regulation in autism spec-trum disorder. Journal of the American Academy of Child \& Adolescent Psychi-atry, 52(7), 679-688. https://doi.org/10.1016/j.jaac.2013.05.006

[21] Totsika, V., Hastings, R. P., Emerson, E., Lancaster, G. A., \& Berridge, D. M. (2011). A population-based investigation of behavioural and emotional problems and maternal mental health: Associations with autism spectrum disorder and in-tellectual disability. Journal of Child Psychology and Psychiatry, 52(1), 91-99. https://doi.org/10.1111/j.14697610.2010.02295.X

[22] Fredrickson, B. L. (2003). The value of positive emotions: The emerging sci-ence of positive psychology is coming to understand why it's good to feel good. American scientist, 91(4), 330-335. https://doi.org/10.1511/2003.4.330

[23] Izard, C. E. (1990). Facial expressions and the regulation of emotions. Journal of personality and social psychology, 58(3), 487. https://doi.org/10.1037/0022-3514.58.3.487

[24] Farb, N.A.; Chapman, H.A.; Anderson, A.K. Emotions: Form follows function. Curr. Opin. Neurobiol. 2013, 23, 393-398. https://doi.org/10.1016/j.conb.2013.01.015

[25] Huy, Q. N. (1999). Emotional capability, emotional intelligence, and radical change. Academy of Management review, 24(2), 325-345. https://doi.org/10.5465/amr.1999.1893939

[26] Ioannidou, F., \& Konstantikaki, V. (2008). Empathy and emotional intelli-gence: What is it really about?. International Journal of caring sciences, 1(3), 118.

[27] Mayer, J.D.; Roberts, R.D.; Barsade, S.G. Human abilities: Emotional intelli-gence. Annu. Rev. Psychol. 2008, 59, 507-536. https://doi.org/10.1146/annurev.psych.59.103006.093646

[28] Gutiérrez-Cobo, M.J.; Cabello, R.; Fernández-Berrocal, P. The relationship be-tween emotional intelligence and cool and hot cognitive processes: A systematic review. Front. Behav. Neurosci. 2016, 10, 101, https://doi.org/10.3389/fnbeh.2016.00101

[29] Oulasvirta, A., Rattenbury, T., Ma, L., \& Raita, E. (2012). Habits make smartphone use more pervasive. Personal and Ubiquitous Computing, 16(1), 105-114. https://doi.org/10.1007/s00779-011-0412-2

[30] Fogg, B. J. (Ed.). (2007). Mobile persuasion: 20 perspectives on the future of behavior change. Mobile Persuasion.

[31] Oinas-Kukkonen, H., \& Harjumaa, M. (2008, June). A systematic framework for designing and evaluating persuasive systems. In International conference on persuasive technology (pp. 164-176). Springer, Berlin, Heidelberg. https://doi.org/10.1007/978-3-540-68504-3_15

[32] Langrial, S., Lehto, T., Oinas-Kukkonen, H., Harjumaa, M., \& Karppinen, P. (2012, July). Native Mobile Applications For Personal Well-Being: A Persua-sive Systems Design Evaluation. In PACIS (p. 93).

[33] Torous, J., Staples, P., \& Onnela, J. P. (2015). Realizing the potential of mo-bile mental health: new methods for new data in psychiatry. Current psychiatry reports, 17(8), 61. https://doi.org/10.1007/s11920-015-0602-0

[34] Carissoli, C., Villani, D., \& Riva, G. (2015). Does a meditation protocol sup-ported by a mobile application help people reduce stress? Suggestions from a controlled pragmatic trial. Cyberpsychology, Behavior, and Social Networking, 18(1), 46-53. https://doi.org/10.1089/ cyber.2014.0062

[35] Little, J. R., Pavliscsak, H. H., Cooper, M., Goldstein, L., Tong, J., \& Fonda, S. J. (2017). Usability of a mobile application for patients rehabilitating in their community. Journal of Mobile Technology in Medicine, 6(3), 14-24. https://doi.org/10.7309/jmtm.6.3.4

[36] Wei, Q., Luo, W., Chiang, S., Kappel, T., Mejia, C., Tseng, D., ... \& Ozkan, H. (2014). Imaging and sizing of single DNA molecules on a mobile phone. ACS nano, 8(12), 1272512733. https://doi.org/10.1021/nn505821y 
[37] Bateman, D. R., Srinivas, B., Emmett, T. W., Schleyer, T. K., Holden, R. J., Hendrie, H. C., \& Callahan, C. M. (2017). Categorizing Health Outcomes and Efficacy of mHealth Apps for Persons With Cognitive Impairment: A Systemat-ic Review. Journal of medical Internet research, 19(8). https://doi.org/10.2196/jmir.7814

[38] Yang, C. H., Maher, J. P., \& Conroy, D. E. (2015). Implementation of behav-ior change techniques in mobile applications for physical activity. American journal of preventive medicine, 48(4), 452-455. https://doi.org/10.1016/j.amepre.2014.10.010

[39] Zhao, J., Freeman, B., \& Li, M. (2016). Can mobile phone apps influence peo-ple's health behavior change? An evidence review. Journal of medical Internet research, 18(11). https://doi.org/10.2196/jmir.5692

[40] Hartin, P. J., Nugent, C. D., McClean, S. I., Cleland, I., Tschanz, J. T., Clark, C. J., \& Norton, M. C. (2016). The empowering role of mobile apps in behav-ior change interventions: The Gray Matters randomized controlled trial. JMIR mHealth and uHealth, 4(3). https://doi.org/10.2196/mhealth.4878

[41] Bice, M. R., Carey, J., Brown, G. A., Adkins, M., \& Ball, J. W. (2016). The Use of Mobile Application to Enhance Learning of the Skeletal System in Intro-ductory Anatomy \& Physiology Students. International J. Kinesiology in High-er Education, 27(1), 16-22.

[42] Shroff, R. H., \& Keyes, C. J. (2017). A proposed framework to understand the intrinsic motivation factors on university students' behavioral intention to use a mobile application for learning. Journal of Information Technology Education: Research, 16, 143-168. https://doi.org/10.28945/3694

[43] Jeno, L. M., Grytnes, J. A., \& Vandvik, V. (2017). The effect of a mobile-application tool on biology students' motivation and achievement in species identification: A Self-Determination Theory perspective. Computers \& Educa-tion, 107, 1-12. https://doi.org/10.1016/ j.compedu.2016.12.011

[44] Johnson, D., Deterding, S., Kuhn, K. A., Staneva, A., Stoyanov, S., \& Hides, L. (2016). Gamification for health and wellbeing: A systematic review of the lit-erature. Internet Interventions, 6, 89-106. https://doi.org/10.1016/j.invent.2016.10.002

[45] Kinnunen, M., Mian, S. Q., Oinas-Kukkonen, H., Riekki, J., Jutila, M., Er-vasti, M., ... \& Alasaarela, E. (2016). Wearable and mobile sensors connected to social media in human well-being applications. Telematics and Informatics, 33(1), 92-101. https://doi.org/10.1016/ j.tele.2015.06.008

[46] Rickard, N., Arjmand, H. A., Bakker, D., \& Seabrook, E. (2016). Development of a mobile phone app to support self-monitoring of emotional well-being: a mental health digital innovation. JMIR mental health, 3(4). https://doi.org/10.2196/mental.6202

[47] Hossain, M. S., \& Muhammad, G. (2017). An emotion recognition system for mobile applications. IEEE Access, 5, 2281-2287. https://doi.org/10.1109/ACCESS.2017.2672829

[48] Yee, H. S. S. (2012, October). Mobile technology for children with Autism Spectrum Disorder: Major trends and issues. In E-Learning, E-Management and E-Services (IS3e), 2012 IEEE Symposium on (pp. 1-5). IEEE.

[49] de Urturi, Z. S., Zorrilla, A. M., \& Zapirain, B. G. (2011, July). Serious Game based on first aid education for individuals with Autism Spectrum Disorder (ASD) using android mobile devices. In Computer Games (CGAMES), 2011 16th International Conference on (pp. 223227). IEEE.

[50] Hansen, O. B., Abdurihim, A., \& McCallum, S. (2013, September). Emotion recognition for mobile devices with a potential use in serious games for autism spectrum disorder. In International Conference on Serious Games Development and Applications (pp. 1-14). Springer, Berlin, Heidelberg. https://doi.org/10.1007/978-3-642-40790-1_1 
[51] Madsen, M., El Kaliouby, R., Goodwin, M., \& Picard, R. (2008, October). Technology for just-in-time in-situ learning of facial affect for persons diagnosed with an autism spectrum disorder. In Proceedings of the 10th international ACM SIGACCESS conference on Computers and accessibility (pp. 19-26). ACM. https://doi.org/10.1145/1414471.1414477

[52] Devecchi, C., Mintz, J., \& March, C. (2009). Supporting user participation in developing mobile technology to help young people with autism: the HANDS smartphone project.

[53] Øhrstrøm, P. (2011). Helping autism-diagnosed teenagers navigate and develop socially using e-learning based on mobile persuasion. The International Review of Research in Open and Distributed Learning, 12(4), 54-71. https://doi.org/10.19173/irrodl.v12i4.878

[54] Jordan, C. J. (2010). Evolution of autism support and understanding via the World Wide Web. Intellectual and developmental disabilities, 48(3), 220-227. https://doi.org/10.1352/19 $\underline{34-9556-48.3 .220}$

[55] Hassan, A., Shafi, M., \& Khattak, M. I. (2016). Multi-touch collaborative ges-ture recognition based user interfaces as behavioral interventions for children with autistic spectrum disorder: A review. Mehran University Research Journal of Engineering \& Technology, 35(4), 543. https://doi.org/10.22581/muet1982.1604.06

[56] Mu-oz, R., Barcelos, T., Noël, R., \& Kreisel, S. (2012, November). Develop-ment of software that supports the improvement of the empathy in children with autism spectrum disorder. In Chilean Computer Science Society (SCCC), 2012 31st International Conference of the (pp. 223-228). IEEE.

[57] Mu-oz, R., Nöel, R., Kreisel, S., \& Mancilla, F. (2012). Proyect@ Emociones: software para estimular el desarrollo de la empatía en ni-os y ni-as con trastor-nos del espectro autista. Nuevas ideas en informática educativa, TISE, 59-64.

[58] Alves, S., Marques, A., Queirós, C., \& Orvalho, V. (2013). LIFEisGAME pro-totype: a serious game about emotions for children with autism spectrum disor-ders. Psychnology Journal, vol. 11, n⿳3.

[59] Fernandes, T., Alves, S., Miranda, J., Queirós, C., \& Orvalho, V. (2011, Octo-ber). LIFEisGAME: A facial character animation system to help recognize facial expressions. In International Conference on ENTERprise Information Systems (pp. 423-432). Springer, Berlin, Heidelberg.

[60] Gay, V., Leijdekkers, P., Agcanas, J., Wong, F., \& Wu, Q. (2013, January). CaptureMyEmotion: Helping Autistic Children Understand their Emotions Us-ing Facial Expression Recognition and Mobile Technologies. In Bled eConfer-ence (p. 10).

[61] Mahesh M., Myunghoon B.S. and Balakrishnan P. (2012). FaceFetch: A User Emotion Driven Multimedia Content Recommendation System Based on Facial Expression Recognition. 2012 IEEE International Symposium on Multimedia (ISM).

[62] Anand, B. Navathe, B.B. et Al. Beyond touch: Natural interactions using facial expressions (2012). IEEE Consumer Communications and Networking Confer-ence, 255 - 259.

[63] Tan, C. T., Harrold, N., \& Rosser, D. (2013, November). Can you CopyMe?: an expression mimicking serious game. In SIGGRAPH Asia 2013 symposium on mobile graphics and interactive applications (p. 73). ACM. https://doi.org/10.1145/2543651.2543657

[64] Cardon, T. A. (2012). Teaching caregivers to implement video modeling imita-tion training via iPad for their children with autism. Research in Autism Spec-trum Disorders, 6(4), 13891400. https://doi.org/10.1016/j.rasd.2012.06.002

[65] Murdock, L. C., Ganz, J., \& Crittendon, J. (2013). Use of an iPad play story to increase play dialogue of preschoolers with autism spectrum disorders. Journal of autism and developmental disorders, 43(9), 2174-2189. https://doi.org/10.1007/s10803-013-1770-6

[66] Deriso, D., Susskind, J., Krieger, L., \& Bartlett, M. (2012, October). Emotion mirror: a novel intervention for autism based on real-time expression recogni-tion. In European Conference 
on Computer Vision (pp. 671-674). Springer, Ber-lin, Heidelberg. https://doi.org/10.1007/ 978-3-642-33885-4 79

[67] Tsangouri, C., Li, W., Zhu, Z., Abtahi, F., \& Ro, T. (2016, November). An interactive facialexpression training platform for individuals with autism spec-trum disorder. In MIT Undergraduate Research Technology Conference (URTC), 2016 IEEE (pp. 1-3). IEEE.

[68] Voon, N. H., Bazilah, S. N., Maidin, A., Jumaat, H., \& Ahmad, M. Z. (2015). Autisay: A mobile communication tool for autistic individuals. In Computa-tional Intelligence in Information Systems (pp. 349-359). Springer, Cham. https://doi.org/10.1007/978-3-319-13153$\underline{5 \quad 34}$

[69] Institut Teknologi Brunei. 2013. EducateMe. [Mobile app]. [Accessed 9 No-vember 2013]. Available from: Apple AppStore.

[70] Kirst, S., Zoerner, D., Schütze, J., Lucke, U., \& Dziobek, I. (2015). Zirkus Empathico: Eine mobile Applikation zum Training sozioemotionaler Kompeten-zen bei Kindern im Autismus-Spektrum. DeLFI 2015--Die 13. E-Learning Fachtagung Informatik.

[71] Zoerner, D., Schütze, J., Kirst, S., Dziobek, I., \& Lucke, U. (2016, July). Zir-kus Empathico: Mobile Training of Socio-Emotional Competences for Children with Autism. In Advanced Learning Technologies (ICALT), 2016 IEEE 16th In-ternational Conference on (pp. 448452). IEEE.

[72] Carvalho, V. H., Brandão, J., Cunha, P., Vasconcelos, J., \& Soares, F. (2015). Tobias in the Zoo-A Serious Game for Children with Autism Spectrum Disor-ders. International Journal of Advanced Corporate Learning (iJAC), 8(3), 23-29. https://doi.org/10.3991/ijac.v8i3.4897

[73] Brandão, J., Cunha, P., Vasconcelos, J., Carvalho, V., \& Soares, F. (2015). An Augmented Reality GameBook for Children with Autism Spectrum Disorders. In The International Conference Focused on e-Learning in the WorNplace.

[74] Shen, X., \& Barakova, E. I. (2016, June). My drama: story-based game for un-derstanding emotions in context. In International Conference on Intelligent Technologies for Interactive Entertainment (pp. 220-230). Springer, Cham.

[75] Model Me Kids LLC (2012). Autism Emotion (Version 4.0). [Mobile Applica-tion Software]. Retrieved from: https://itunes.apple.com/us/app/autism-emotion/id550027186? $\mathrm{mt}=8$

[76] Hamaguchi Pediatric Speech-Language Patholologists, Inc, a Professional Cor-poration. Between the Lines. [Mobile Application Software]. Retrieved from: http://www.hamaguchiapps.com/between-the-lines.html

[77] WebTeam Corporation. What's the Expression-All Ages (Version 2.0.0) [Mo-bile Application Software]. Retrieved from: https://itunes.apple.com/us/app/whats-the-expression-all ag-es/id505096524?platform=iphone\&preserveScrollPosition=true\#platform/iphone

[78] Innovative Mobile Apps Ltd (C) Alligator Apps. Touch and Learn - Emotions (Version 3.0) [Mobile application software]. Retrieved from: https://itunes.apple.com/us/app/touch-andlearn-emotions/id451685022? $\mathrm{mt}=8$

[79] Touch Autism (2012). Emotions and Feelings Social Story (Version 3.2) [Mo-bile application software]. Retrieved from: http://appshopper.com/education/emotions-and-feelings-social-story

[80] Auticiel. (2014). Autimo (Version 3.3.7) [Mobile application software]. Re-trieved from: https://itunes.apple.com/us/app/autimo-amikeo-apps/id495565736?mt=8

[81] I Can Do Apps, LLC. (2013). Emotions 2 from I Can Do Apps (Version 1.3) [Mobile application software]. Retrieved from: https://itunes.apple.com/ca/app/emotions-2-from-ican-doapps/id661208169?mt=8.

[82] Rufus Robot, Inc. (2014). Learning with Rufus: Emotions (Version 1.0.4) [Mobile application software]. Retrieved from: http://www.rufusrobot.com/. 
[83] Everyday Speech. (2014). Let's Learn Emotions: Emotion Recognition (Version 1.2.1) [Mobile application software]. Retrieved from: https://itunes.apple.com/us/app/lets-learn-emotions-pro-emotion-recognition-for-speech/id908762349? $\mathrm{mt}=8$.

[84] Virtual Eye See Inc. (2014). Discovering Emotions with Zeely [Mobile applica-tion software]. Retrieved from: http://zeelyadventures.com/

[85] Samsung LOOK AT ME (2014). LOOK AT ME (Version 3.12.20141219) [Mo-bile application software]. Retrieved from: https://news.samsung.com/global/samsung-introduceslook-at-me-app-to-help-children-with-autism-communicate-better

[86] Torrado, J. C., Gomez, J., \& Montoro, G. (2017). Emotional Self-Regulation of Individuals with Autism Spectrum Disorders: Smartwatches for Monitoring and Interaction. Sensors, 17(6), 1359. https://doi.org/10.3390/s17061359

[87] White, S. W., Abbott, A. L., Wieckowski, A. T., Capriola, N. N., Aly, S., \& Youssef, A. (2017). Feasibility of Automated Training for Facial Emotion Ex-pression and Recognition in Autism. Behavior Therapy.

[88] Shane, H. C., \& Albert, P. D. (2008). Electronic screen media for persons with autism spectrum disorders: Results of a survey. Journal of autism and develop-mental disorders, 38(8), 1499-1508. https://doi.org/10.1007/s10803-007-0527-5

[89] Sung, A. N., Bai, A., Bowen, J. G., Xu, B., Bartlett, L. M., Sanchez, J. C., ... \& Tanaka, J. W. (2015). From the small screen to the big world: mobile apps for teaching real-world face recognition to children with autism. Advanced Health Care Technologies, 1, 37-45.

[90] Gay, V., \& Leijdekkers, P. (2014). Design of emotion-aware mobile apps for au-tistic children. Health and Technology, 4(1), 21-26. https://doi.org/10.1007/s12553-013-0066-3

[91] Al-Wakeel, L., Al-Ghanim, A., Al-Zeer, S., \& Al-Nafjan, K. (2015). A Usabil-ity Evaluation of Arabic Mobile Applications Designed for Children with Spe-cial Needs--Autism. Lecture Notes on Software Engineering, 3(3), 203. https://doi.org/10.7763/LNSE.2015.V3.191

\section{$5 \quad$ Authors}

Chara Papoutsi is a $\mathrm{PhD}$ Candidate in Information and Communication Systems Engineering at the University of the Aegean in Samos, Greece. She holds a Master degree in Applied Pedagogy at the National and Kapodistrian University of Athens. She is a teacher in a primary school. She has publications on empathy and emotional intelligence and she is also with NCSR DEMOKRITOS, Institute of Informatics and Telecommunications, Net Media Lab, Athens, Greece. (e-mail: papoutsi.xara@yahoo.com).

Athanasios Drigas is a Research Director at IIT-N.C.S.R. Demokritos. He is the Coordinator of Telecoms Lab and founder of Net Media Lab since 1996. From 1990 to 1999 he was the Operational manager of the Greek Academic network. He has been the Coordinator of Several International Projects, in the fields of ICTs, and eservices (elearning, e-psychology, e-government, e-inclusion, e-culture etc). He has published more than 270 articles, 7 books, 25 educational CD-ROMs and several patents. He has been a member of several International committees for the design and coordination of Network and ICT activities and of international conferences and journals. Also he has accepted several distinctions for his work (articles, projects, patents) (e-mail: dr@iit.demokritos.gr). 
Charalabos Skianis is currently Assiociate Professor in the Department of Information and Communication Systems at the University of the Aegean in Samos, Greece. He holds a PhD degree in Computer Science, University of Bradford, United Kingdom and a BSc in Physics, Department of Physics, University of Patras, Greece. His current research activities take upon Novel Internet Architectures and Services, Cloud Computing \& Networking, Energy \& Context aware Next Generation Networks and Services, management aspects of mobile and wireless networks, ubiquitous and pervasive computing and End-to-End Quality of Service provisioning in heterogeneous networks environment. He has been actively working on the area of computer and communication systems performance modeling and evaluation where he has introduced alternative methodologies for the approximate analysis of certain arbitrary queuing network models. He is also keen in traffic modeling and characterization, queuing theory and traffic control of wired and wireless telecommunication systems. His work is published in journals, conference proceedings and as book chapters and has also been presented in numerous conferences and workshops. He is at the editorial board of journals, a member of pronounced professional societies (senior member of IEEE) and an active reviewer for several scientific journals. He is an active member of several Technical Committees. He is currently project coordinator for ICT FP7 PASSIVE project (e-mail: cskianis@aegean.gr).

Article submitted 20 June 2018. Final acceptance 24 October 2018. Final version published as submitted by the authors. 